\title{
Empresas familiares de inmigrantes
}

\author{
Paola Martínez \\ Universitat Autònoma de Barcelona. Departament de Sociologia \\ Grup d'Estudis d'Immigració i Minories Ėtniques (GEDIME) \\ 08193 Bellaterra (Barcelona). Spain
}

\section{Resumen}

Las empresas familiares de inmigrantes se caracterizan por la peculiar relación entre empresa y familia en un contexto migratorio. El análisis de la dimensión familiar en estas empresas se estructura en tres ejes: la familia como recurso de clase, la familia como recurso étnico y, finalmente, el rol de la mujer dentro de las empresas familiares de inmigrantes.

Palabras clave: empresas familiares, negocios étnicos, familia.

\section{Abstract. Immigrants running family businesses}

Immigrant family businesses have, in a migratory context, a peculiar relation between business and family. Analysis of a family dimension in these businesses is based on the three following cruxes: family as a class resource, family as an ethnic resource and woman role within immigrant family businesses.

Key words: family businesses, ethnic businesses, family.

\section{Familia y empresa en un contexto migratorio}

La definición de «empresas familiares de inmigrantes» surge al cruzar dos tipologías o variables que caracterizan a estas empresas: por un lado, se trata de empresas estructuradas como empresas familiares y, por otro lado, estas empresas familiares han sido creadas por empresarios inmigrantes. De modo que el factor que distingue este tipo de empresas de las empresas familiares de autóctonos es el modelo de familia.

En las empresas de inmigrantes, la familia ocupa un lugar destacado en los diferentes ciclos temporales de la empresa — creación, mantenimiento, expansión y sucesión o cierre- (Gallo, 1998). En cada etapa, la familia desempeña un papel predominante distinto - familia como recurso de clase o familia como recurso étnico-. La utilización de los recursos de clase en la familia adquiere mayor protagonismo en la fase inicial de la empresa y en la sucesión. El recurso a la solidaridad familiar para llevar a cabo el proyecto empresarial tiene más fuerza en los primeros momentos de la empresa, así como en las etapas en las que el negocio entra en crisis. 
El capital social obtenido de la familia como recurso de clase es un elemento crucial en la carrera empresarial de los emprendedores entrevistados (Solé y Parella, 2005). Este capital social familiar resulta clave cuando en la empresa familiar se produce la sucesión. En este sentido, en el trabajo de campo realizado, se observa que la sucesión del negocio en un contexto migratorio rebasa los límites de la dimensión familiar, material y territorial. Por ejemplo, encontramos como los negocios familiares se perpetúan en el país de destino escogido en la emigración. También existen casos en los que se ha producido una «sucesión» del tipo de negocio familiar de una familia a otra. En definitiva, la «sucesión» en la actividad emprendedora puede entenderse de tres formas diferentes. En primer lugar, la idea clásica que tenemos de "sucesión» en la empresa: el traspaso del negocio de padres a hijos. En segundo lugar, otra especie de sucesión ocurre cuando lo que se traspasa no es el negocio, sino el espíritu empresarial y las enseñanzas que comporta, en lo que podríamos denominar una «sucesión no material». Por último, cuando algunos autores (Barret, Jones y McEvoy, 2001; Solé y Parella, 2005) hablan del proceso de sustitución, por parte de los empresarios inmigrantes, de los mismos negocios - pequeños comercios- abandonados por los autóctonos, no están hablando sino de un tipo de «sucesión no familiar».

La familia también es un recurso material, sobre todo como mano de obra, que constituye la ventaja competitiva por excelencia en la empresa familiar. La utilización de mano de obra familiar de modo informal provee al empresario de una plantilla de trabajadores flexible y supone un ahorro de costes burocráticos y de contratación. El recurso a la familia como mano de obra barata o gratuita resulta más viable en el caso de estructuras familiares tradicionales que en otros tipos de familia.

\section{La mujer inmigrante en la empresa familiar}

El modelo de familia también determina las relaciones entre la vida laboral y familiar de las mujeres inmigradas que son empresarias o trabajadoras de la empresa familiar. La mujer inmigrante, dentro de la empresa familiar, ha asumido hasta tres papeles diferentes: $a$ ) las mujeres empresarias — que son la cabeza visible, en solitario o en sociedad, de la estructura empresarial—; $b$ ) las mujeres que ocupan un puesto reconocido dentro de la empresa, pero por debajo del estrato jerárquico más alto, y $c$ ) las mujeres que colaboran en el negocio con un papel no visible (Kontos, 2000). La estrategia de conciliación seguida por estas mujeres a la hora de conciliar el trabajo en la empresa familiar con sus responsabilidades reproductivas, permite la perpetuación de modelos de división sexual del trabajo de corte tradicional. Si bien es cierto que estas mujeres se incorporan a la esfera laboral, se siguen ocupando también de las mismas responsabilidades reproductivas. Lejos de liberarse del espacio doméstico, asumen una "doble presencia» en su vida cotidiana.

Las mujeres empresarias con cargas familiares que se han entrevistado, se diferencian de las mujeres empresarias autóctonas en que, en muchos casos, 
no poseen una red familiar extensa en la sociedad de acogida que les permita distribuir la carga de las tareas reproductivas. Para ellas, la flexibilidad horaria de la que disponen al ser empresarias, es una ventaja. Por otra parte, estas mujeres inmigradas tampoco tienen el mismo nivel de acceso a las políticas sociales que las mujeres autóctonas. Estos dos elementos — red familiar y políticas sociales - determinan estrategias de conciliación tradicionales y patriarcalistas que se perpetúan en la estructura de la empresa familiar.

\section{Estado de la investigación}

Esta investigación sobre las empresas familiares creadas por emprendedores de origen inmigrante, responde a la lógica de la exploración. La aproximación al estudio de las empresas familiares de inmigrantes se fundamentó en un marco teórico multidisciplinario. Por lo que se refiere a la empresa, se abordan las teorías sociológicas de los negocios étnicos, en concreto, la teoría de la incrustación mixta (Kloosterman y Rath, 2001). Por otra parte, las teorías de la empresa familiar, desde la disciplina de la economía de la empresa, completan los aspectos más operativos del modelo. En cuanto a la familia, se han trabajado las diferentes corrientes teóricas de la perspectiva feminista de la sociología de la familia.

El trabajo de campo consiste, principalmente, en la realización de entrevistas en profundidad con empresarios inmigrantes. Las entrevistas se han llevado a cabo en dos fases que discurren entre enero de 2003 y mayo de 2006.

En junio de 2006, acaba la redacción final del proyecto y comienza una nueva etapa de la investigación, donde se profundizará en el estudio de la dimensión familiar en las empresas familiares de inmigrantes.

\section{Bibliografía}

BARRET, G.; Jones, T.; MCEVOY, D. (2001). «Socio-economic and policy dimensions of the mixed embeddedness of ethnic minority business in Britain». Journal of Ethnic and Migration Studies, 27: 241-258.

Gallo, M. A. (1998). La successió a l'empresa familiar. Barcelona: Servei d'Estudis de La Caixa.

KLOOSTERMAN, R.; RATH, J. (2001). "Immigrant entrepreneurs in advanced economies: mixed embeddedness further explored». Journal of Ethnic and Migration Studies, 27: 189-201.

KonTOS, M. (2000). «Self- Employment of Migrant Women and Ethnic Structures». En: Ethnic Neighborhoods in European Cities: Entrepreneurship, Employment and Social Order (Cologne).

Solé, C.; Parella, S. (2005). Negocios étnicos. Los comercios regentados por inmigrantes no comunitarios en Cataluña. Barcelona: Fundació CIDOB. 